\title{
Dental discoloration prevalence of rural and urban population in Ninevah Governorate, Mosul, Iraq. A comparative study
}

\author{
Ne'am N AL-YOUSIFANI* \\ Ma'an M NAYEF**
}

\begin{abstract}
ABSTRAC'T
The aims of this study are to determine and compare the prevalence of teeth discoloration in an urban and rural area in Mosul City.

A sample of (228) subjects aged (5-44) years was examined. The sample was divided into four age groups $(5-14),(15-24),(25-34)$ and $(35-44)$ years.

The results revealed a significant difference in the prevalence of teeth discoloration between rural and urban areas, (80.7) and (56.1), respectively. Also the results showed that natural and acquired stains in general were greater than other causes of the staining; the highest level of natural discoloration found to be due to habits. There were no significant differences between age groups and sex.
\end{abstract}

Key Words: Discoloration, urban, rural

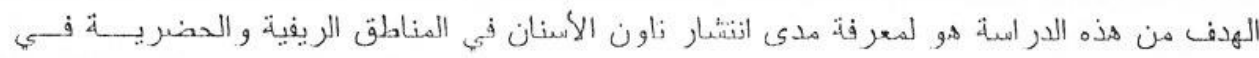

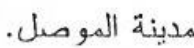

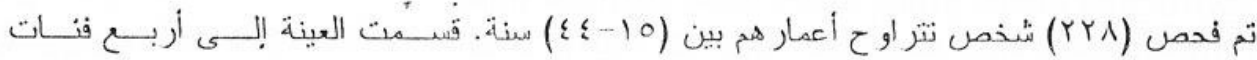

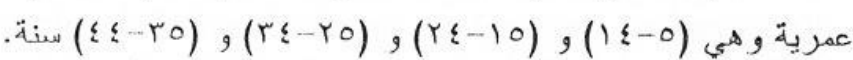

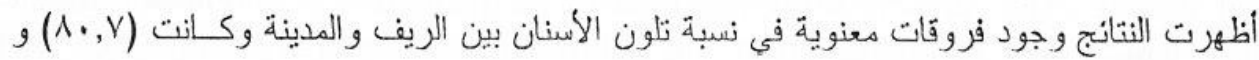

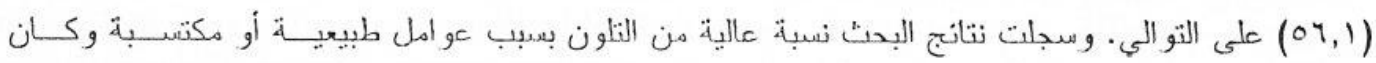

السبب الرنيسي لهذه العوامل هو العادات السيئة. لم بظهر أي فروقات معنو ية بين الفنات العمرية أو الجنس.

* Nc'am Najecb AL-YOUSIFANI: BDS, MSc: Assistant Lecturer.

** Ma'an Mwafaq NAYEF; BDS, MSc: Assistant Lecturer.

Department of Conservative Dentistry, College of Dentistry. University of Mosul, Mosul, IRAQ. 


\section{INTRODUCTION}

Throughout history, dentistry has concentrated its efforts on the relief of pain and the restoration of function. Only recently has attention been focused on cosmetics as a special dental discipline ${ }^{(1)}$.

Esthetic treatment of teeth is an increasingly important aspect of the modern dental practice, one of the more common esthetic problems is discoloration ${ }^{(2)}$, particularly when it involves anterior teeth which might be significant enough to force the individual seeking a dental treatment. There are many causes of discoloration; most commonly causes result by caffeine and tobacco, aging, hereditary factors, severe jaundice, trauma to the tooth, dental fluorosis and certain medicaments (like tetracycline) can also result in darkening the teeth.

Studies conducted in developing countries have reported a relationship between sociocconomic stalus and oral health $\left.{ }^{(3} 6\right)$.

A study on rural areas concluded that discoloration was prevalent problem in rural areas particularly as a result of bad oral hygiene ${ }^{(7)}$.

Low socioeconomic level, lack of education and dietary habits in rural areas might significantly participate in increasing the chance of developing teeth discoloration ${ }^{(7)}$.

In urban area, the higher level of education and more knowledge about dental health performed more regular oral hygiene measurements.

The aims of this study are comparison of the prevalence and severity of teeth discoloration between urban and rural community populations in Ninevah City.

\section{MATERIALS AND MEIIIODS}

Onc hundred fourteen subjects aged (5-44) years were selected randomly from patients who were attending the Conservative Department, College of Dentistry in Mosul University. Those palients were compared with matched nge and sex (114) individuals sclected randomly from the Sharkhan village located few kilometers to the north of Mosul City.

Oral examination for collection of discoloration data was performed with dental mirror and dental probe under good artificial light.

Information was recorded in case sheet, which includes the main causes of discoloration, natural or acquired stain, developmental defects and iatrogenic or inflected causes. The present study was focused on the natural or acquired causes of the stain, which was estimated from the following: Intra-pulpal hemorrhage, pulp necrosis, calcific metamorphosis, aging and habits duc to tea, coffee and smoking. In addition to these, informations about name, age, sex were registered. The populations of each sample were divided into four age groups (5-14), (15-24), (25-34) and (3544) years.

Statistical analysis of the data includes:

(1) Classifications of data and calculation of frequencies.

(3) Comparison between the two groups were tested statistically by means of chi square test at $(p<0.05)$ level of significance. 


\section{RESULTS}

Table (1) shows the distribution of the examined sample by age and sex. The highest percentage of the examined samples presented at (5-14) years for both urban and rural areas. The lowest percentage of samples was presented at (25-34) years.

The number and percentage of subjects exhibited discoloration according to the causes in each age group demonstrated in table (2). There was significant difference in discoloration between rural and urban areas (80.7 and 56.1), respectively; that means less than $(20 \%)$ of the examined subjects in rural area did not have any type of discoloration in their teeth, while in urban area more than $(50 \%)$ of the examined individuals have no discoloration in their teeth.

The natural or acquired stains in general were greater than other causes of discoloration in all age groups and for both locations (rural and urban). The highest level of natural cause found to be due to habits (tea, coffee and smoking) in all age groups except the last one (35-14) years, the percentage of discoloration due to aging was significantly increased as compared with other age groups (table 3 ).

Table (4) displayed the total statistical analysis of the results. The differences in teeth discoloration according to the age groups were significant for (5-14) age group and (25-34) age group, while it was non-significant for the (15-24) age group and last (35-44) age group.

There was no difference in the teeth discoloration between total males and total females for the sample at all (rural and urban).

Table (1): Number and percentage distribution of the examined sample by age and sex

\begin{tabular}{|c|c|c|c|c|c|c|c|c|c|c|c|c|}
\hline \multirow{3}{*}{ (x) } & \multicolumn{6}{|c|}{18.61 .1} & \multicolumn{6}{|c|}{ Rurat } \\
\hline & \multicolumn{2}{|c|}{ Miti: } & \multicolumn{2}{|c|}{ Trinue } & \multicolumn{2}{|c|}{ 1014L } & \multicolumn{2}{|c|}{ Milic } & \multicolumn{2}{|c|}{ Ironivie } & \multicolumn{2}{|c|}{ K } \\
\hline & No. & 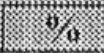 & No. & $\%$ & Vis. & . & No. & 4 & Vo & 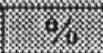 & Ku & r. \\
\hline 5. & 25 & 1 & 17 & 14.93 & 42 & 685 & 26 & 28 & 18 & 15.79 & 44 & 38.5 \\
\hline 15 & 17 & 14.92 & 10 & 0 & 2 & 23 & 18 & 15. & 9 & 7.89 & 27 & 23.5 \\
\hline $2 x-3$ & 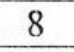 & & 12 & 10.52 & 20 & 17.5 & 7 & & 12 & 10.53 & 19 & 16.6 \\
\hline 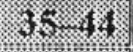 & 8 & 7.01 & 17 & 14.91 & 25 & 21.92 & 0 & 5. & 18 & 15.79 & 24 & 20.9 \\
\hline I ron & 58 & 50.86 & 56 & 49.14 & 114 & 100.00 & 57 & 50.00 & 57 & 50.00 & 114 & 100.0 \\
\hline
\end{tabular}


Table (2): Number and percentage of examined individuals according to the causes of discoloration by age and sex

\begin{tabular}{|c|c|c|c|c|c|c|c|c|}
\hline \multirow{2}{*}{ (A.t) } & \multirow[t]{2}{*}{ 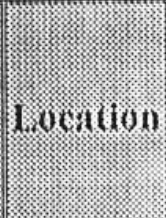 } & \multirow[t]{2}{*}{ Sw } & \multicolumn{2}{|c|}{ 1915colotititil } & \multicolumn{2}{|c|}{ 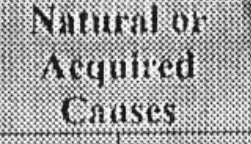 } & \multicolumn{2}{|c|}{ a a.m. } \\
\hline & & & No. & $\%$ & No. & 8. & No. & (8) \\
\hline \multirow{7}{*}{ in: } & \multirow{3}{*}{ Rninil } & Milies & 2 & 7.7 & 18 & 69.2 & 6 & 23.0 \\
\hline & & Irenintes & 4 & 22.2 & 13 & 72.2 & 1 & 5.5 \\
\hline & & Totil & 6 & 13.6 & 31 & 70.4 & 7 & 15.9 \\
\hline & \multirow{4}{*}{ Iriban } & Malles & 12 & 56.0 & 10 & 40.0 & 1 & 4.0 \\
\hline & & Ifentilles & 10 & 5.88 & 4 & 23.5 & 3 & 17.6 \\
\hline & & Totul & 22 & 57.1 & 14 & 33.3 & 7 & 9.5 \\
\hline & & Malles & 5 & 27.7 & 12 & 66.6 & 1 & 5.5 \\
\hline \multirow{5}{*}{12} & \multirow[t]{2}{*}{ Ruril } & I losin ilos & 5 & 55.5 & 4 & 44.4 & 1 & 0 \\
\hline & & $1 / 0111$, & 10 & 37.0 & 16 & 59.2 & 1 & 3.7 \\
\hline & \multirow{3}{*}{ U.1bin } & Nints: & 11 & 64.7 & 5 & 29.4 & 1 & 5.8 \\
\hline & & Jocuniles & 5 & 50 & 3 & 30.0 & 2 & 20.0 \\
\hline & & 1 otal & 16 & 59.2 & 8 & 29.6 & 3 & 11.1 \\
\hline \multirow{6}{*}{ ? } & \multirow{3}{*}{ Rumal. } & Minles & 1 & 14.2 & 6 & 85.7 & 1 & 0 \\
\hline & & Tiemalles & 1 & 8.3 & 6 & 50.0 & 5 & 41.6 \\
\hline & & Totin! & 2 & 10.5 & 12 & 63.1 & 5 & 26.3 \\
\hline & \multirow{3}{*}{ (Wiballi } & Mules & 4 & 50.0 & 2 & 25.0 & 2 & 25.0 \\
\hline & & Fouthales & 8 & 5.3 .3 & 5 & 33.3 & 2 & 13.3 \\
\hline & & $101 \mathrm{n}$ & 12 & 52.1 & 7 & 30.4 & 4 & 17.3 \\
\hline \multirow{6}{*}{ in } & \multirow{3}{*}{ Rurnil. } & Malus & () & 0 & 6 & 1000 & 1 & () \\
\hline & & roninilss & 2 & 11.11 & 13 & 72.2 & 3 & 16.6 \\
\hline & & 19.041. & 2 & 8.3 & 19 & 75.0 & 3 & 12.5 \\
\hline & \multirow{3}{*}{$10.10: 11$} & Milles: & 1 & 12.5 & 5 & 62.5 & 2 & 25.0 \\
\hline & & 1. trivives. & 5 & 27.7 & 9 & 50.0 & 3 & 27.7 \\
\hline & & $101 \mathrm{nl}$ & 6 & 23 & 14 & 53.8 & 7 & 26.9 \\
\hline \multicolumn{3}{|c|}{ Ional Minles } & 37 & 32.4 & 64 & 56.1 & 13 & 11.4 \\
\hline \multicolumn{3}{|c|}{ Totul licuniles } & 40 & 35.0 & 57 & 50.0 & 19 & 16.6 \\
\hline \multicolumn{3}{|c|}{10011 Rural } & 20 & 17.5 & 78 & 68.4 & 16 & 14.1 \\
\hline \multicolumn{3}{|c|}{ Total U.ban. } & 56 & 49.1 & 43 & 37.6 & 19 & 16.6 \\
\hline
\end{tabular}


Table (3): Number and percentage of the examined individuals according to the different types of acquired stain

\begin{tabular}{|c|c|c|c|c|c|c|c|c|c|c|c|}
\hline \multirow[t]{2}{*}{ (1) } & \multirow[t]{2}{*}{ I outarin } & \multicolumn{2}{|c|}{ Hinlitis } & \multicolumn{2}{|c|}{$\begin{array}{l}\text { Julis } \\
\text { Necrosis }\end{array}$} & \multicolumn{2}{|c|}{ 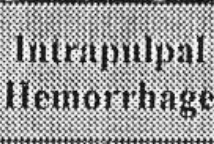 } & \multicolumn{2}{|c|}{ 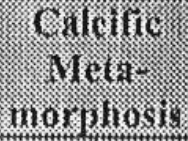 } & \multicolumn{2}{|c|}{ Discolom } \\
\hline & & No. & $\%$ & (xis. & $1 / 6$ & No & $\%$ & Nou & 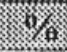 & No. & 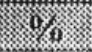 \\
\hline \multirow{2}{*}{5.14} & 13urilu & 30 & 68.1 & 1 & 2.2 & / & 0 & 1 & 0 & 1 & 0 \\
\hline & Lrban & 14 & 33.3 & I & 0 & I & 0 & 1 & 0 & 1 & 0 \\
\hline \multirow{2}{*}{$15 \cdot-24$} & Irinul & 15 & 55.5 & 1 & 3.7 & 1 & 0 & 1 & 0 & 1 & 0 \\
\hline & 14 ban & 7 & 25.9 & 1 & 3.7 & 1 & 0 & 1 & 0 & 1 & 0 \\
\hline \multirow{2}{*}{$25 \cdot 34$} & Irin nil & 7 & 36.7 & I & 0 & 2 & 10.1 & 1 & 5.3 & 2 & 10.5 \\
\hline & Urban & 6 & 26.0 & 1 & 0 & 1 & 0 & 1 & 4.3 & 1 & 0 \\
\hline \multirow{2}{*}{$35=14$} & $1311 \%$ & 10 & 41.7 & I & 0 & 1 & 4.1 & 1 & 0 & 8 & 33.3 \\
\hline & It ban & 4 & 15.3 & 1 & () & 1 & 0 & 1 & 0 & 10 & 38.4 \\
\hline
\end{tabular}

Table (4): Difference between the affected individuals by discoloration according to the area

\begin{tabular}{|c|c|c|c|c|c|}
\hline A ge & Trun! & V. banu & 13 & 7) vilue & Sigunfiu ture \\
\hline 5.11 & 38 & 21 & 17.91 & $<0.05$ & $\mathrm{~S}$ \\
\hline 15.24 & 17 & 11 & 2.67 & $<0.05$ & N.S \\
\hline 25,34 & 17 & 11 & 8.12 & -0.05 & $S$ \\
\hline $35 \cdot 14$ & 22 & 21 & 1.85 & $<0.05$ & N.S \\
\hline Tolal & 94 & 64 & 25.44 & $<0.05$ & $\mathrm{~S}$ \\
\hline
\end{tabular}

$\chi^{2}$ Chi-square test; S: Significant: N.S: Non significant.

\section{IDISC.USSION}

The results of the study showed that the pereentage of the teeth discoloration was higher in rural individual than urban ones, with a statistically significant difference

This low percentage of individual that did not have any type of discoloration in rural areas as compared with urban, reflects the unawareness of importance of oral hygiene in rural area and indicated that rural person has very low dental health education. Also, the results revealed the low interest of rural area about dental programs particularly regarding their cosmetic appearance

These results were in agreement with other studies ${ }^{(7.8)}$, which found higher percentage of population of rural area not attending dental clinic in spite of large number of them had carious defect.

In unban area more than $(50 \%)$ of the individuals did not have any type of tecth discoloration and this percentage significantly differs than rural area. This may be attributed to the reason that people in urban area had high level of education and had more knowledge about dental health, perform more regular oral hygiene measure and more regular in their visits for prolessional cleaning and other preventive measures (9). Therefore, this study showed that discoloration treatment needs were massive in rural area as the disease was high prevalent. 
The percentage of the natural or acquired stain was greater than other causes of discoloration in both rural and urban areas, and mostly due to habits cause (smoking, tea or coffee). This is true for all age groups. The last age group (35-44) reveals increase in the percentage of discoloration due to aging and this is significant for both locations (rural, urban), as the tooth ages, there are several changes take place, from those, deposition of secondary dentin, recession of the pulp from the occlusal surfaces. For this reason the teeth that have been in service for many years are bound to become darker, owving to the change in color of both the enamel and dentin.

There was no difference in discoloration between total males and females, and this is in agreement with other study (10) who found no sex difference, but disagreement with other one (11) that showed a high dental stain in males, and other who revealed that the dental stain in females is greater than males ${ }^{(12)}$. The discoloration problems of both locations (urban, rural) can be managed by providing health education programs to the population to improve their oral hygiene.

From the finding of the present study, it was concluded that discoloration problem was more prevalent in rural area, particularly as a result of bad oral hygiene, or due to habits. Hence, the priority of treatment should be given to the more common causes.

\section{REFERENCES}

1. Arens D. The role of bleaching in esthetics. Dent (lin North Am. 1989; 23: 319-335.

2. Cvitko E, Denchy GE, Swift EJ, Pires J. Bond strength of composite resin to enamel bleached with carbanide peroxide. J lsisthet I) ent. 199); 3: 100-102.

3. $\mathrm{N}-\Lambda$ jrab MGh. Dental fluorosis and dental caries prevalence in Iracpi children living in areas with low and high level of natural fluoride. MSc thesis submitted to the College of Dentistry, Mosul University. 2000.

4. Makani $\mathrm{L}, \mathrm{A}$. Oral hygiene and gingival health among adolescents and adult population (15-44) in Sharkhan village. Al Rafidain Dent J. 2001; 1: 1-7.

5. Khamrco TY, $\Lambda \mathrm{I}$ Naimi RJ, $\Lambda \mathrm{I}$-Mukhtar BS. The effect of social class on periodontal condition and treatment needs of (13-15) year old students in Mosul City, Ninevah, Iraq. Al Rafidain Dent J. 2001; 1: 78-84.

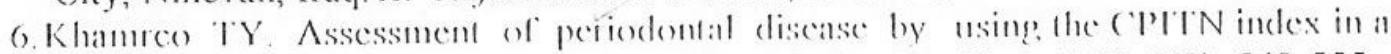
population of rural area, Ninevah, Irac. Lecrst Medittr Health J. 1999; 5(3): 549-555.

7. Nayef MM, Salman TH, Ne'ma MM. Prevalence of dental discoloration among (544) years population in Sharkhan village, Ninevah Governorate, Mosul, Iraq. Al Rafickin I ent.J. 2001; I (sp iss): 327-334.

8. Khamreo TY, Abdal AK. Dental health status in Sharkhan village, Mosul. Iraqi Dent J. 2000; 6: 150-150.

9. Beal JF. Social factor and preventive dentistry. In: Murray JJ (Ed). The Prevention of Dental Discase. Oxford University Press. 1989; Pp: 373

10. Abdul-Hameed AR. Extrinsic dental stain among Iraqi children and adolescents. MSc thesis submitted to the College of Dentistry, University of Baghdad. 1989.

11. Al-Azawi LA. Extrinsic dental stains among 15 years old students in the central region of Irac. Accepted for publication in Iraqi Dent J. 2001.

12. Dayan D, Hicfferman $\Lambda$, Geardkim G, Begleites $\Lambda$. Tooth discoloration, extrinsic and intrinsic factors. Quintess Int J. 1983; 14: 195-198. 